\title{
Epigenetic reprogramming converts human Wharton's jelly mesenchymal stem cells into functional cardiomyocytes by differential regulation of Wnt mediators
}

\author{
G. Bhuvanalakshmi ${ }^{1}$, Frank Arfuso ${ }^{2,3}$, Alan Prem Kumar ${ }^{1,4,5,6,7,8}$, Arun Dharmarajan ${ }^{2}$ and Sudha Warrier ${ }^{1,6,9^{*}}$
}

\begin{abstract}
Background: Lineage commitment of mesenchymal stem cells (MSCs) to cardiac differentiation is controlled by transcription factors that are regulated by epigenetic events, mainly histone deacetylation and promoter DNA methylation. Here, we studied the differentiation of human Wharton's jelly MSCs (WJMSCs) into the cardiomyocyte lineage via epigenetic manipulations.

Methods: We introduced these changes using inhibitors of DNA methyl transferase and histone deacetylase, DC301, DC302, and DC303, in various combinations. We characterized for cardiogenic differentiation by assessing the expression of cardiac-specific markers by immunolocalization, quantitative RT-PCR, and flow cytometry. Cardiac functional studies were performed by FURA2AM staining and Greiss assay. The role of Wnt signaling during cardiac differentiation was analyzed by quantitative RT-PCR. In-vivo studies were performed in a doxorubicin-induced cardiotoxic mouse model by injecting cardiac progenitor cells. Promoter methylation status of the cardiac transcription factor Nkx2.5 and the Wnt antagonist, secreted frizzled-related protein 4 (sFRP4), after cardiac differentiation was studied by bisulfite sequencing.

Results: By induction with DC301 and DC302, WJMSCs differentiated into cardiomyocyte-like structures with an upregulation of Wnt antagonists, SFRP3 and SFRP4, and Dickkopf (Dkk)1 and Dkk3. The cardiac function enhancer, vinculin, and DDX20, a DEAD-box RNA helicase, were also upregulated in differentiated cardiomyocytes. Additionally, bisulfite sequencing revealed, for the first time in cardiogenesis, that sFRP4 is activated by promoter CpG island demethylation. In vivo, these MSC-derived cardiac progenitors could not only successfully engraft to the site of cardiac injury in mice with doxorubicin-induced cardiac injury, but also form functional cardiomyocytes and restore cardiac function.
\end{abstract}

Conclusion: The present study unveils a link between Wnt inhibition and epigenetic modification to initiate cardiac differentiation, which could enhance the efficacy of stem cell therapy for ischemic heart disorders.

Keywords: Mesenchymal stem cells, Epigenetic modification, Cardiomyocytes, DNA methyltransferase, Histone deacetylase, Wharton's jelly

\footnotetext{
* Correspondence: sudha.warrier@manipal.edu

${ }^{1}$ Division of Cancer Stem Cells and Cardiovascular Regeneration, Manipal Institute of Regenerative Medicine, Manipal University, Bangalore 560065 , India

${ }^{6}$ School of Biomedical Sciences, Curtin Health Innovation Research Institute,

Curtin University, Perth, WA 6102, Australia

Full list of author information is available at the end of the article
} 


\section{Background}

Cardiac development is exquisitely regulated by a plethora of transcription factors, and its complexity is reflected by the fact that mutations in these factors during development can cause congenital heart diseases at birth. Despite advances in the prevention and management of cardiovascular diseases, this multifactorial disease remains the leading global cause of death, accounting for 17.3 million deaths per year, and is expected to grow to more than 23.6 million by 2030 [1] As the regenerative potential of cardiac tissue is limited in adult life, leading to degeneration in pathological conditions such as myocardial infarction, stem cell-based therapy has been increasingly used to improve outcome in cardiac disease. One of the most promising advances in stem cell therapy for cardiovascular diseases has been the allogeneic transplantation of immunocompromised mesenchymal stem cells (MSCs) into patients, which is now in an immune-privileged clinical trial [2]. MSCs from various fetal and adult tissues are excellent viable options for stem cell therapy for cardiac degeneration.

Commitment to the cardiac lineage is initiated by specific signals that regulate a set of transcription factors which program cardiogenesis. After the generation of cardiomyocytes, there is proliferation throughout development so that the fetal heart increases in size. Soon after birth, there is limited proliferation, with the cells undergoing terminal differentiation and eventually permanently exiting from the cell cycle [3]. During myocardial damage and injury, cardiac progenitor cells migrate to the site of injury to augment the limited mitotic capacity of terminally differentiated cardiomyocytes and eventually regenerate the myocardium [4]. However, these cell populations are very few in number and decrease significantly during the aging process, thereby compromising the regenerative process [5]. Pluripotent, embryonic and mesenchymal stem cells, by virtue of their ability to self-renew and differentiate into multiple lineages, are emerging as viable alternatives to replace the lost cardiomyocytes [6, 7]. MSCs from adult tissues differ from MSCs from tissues of fetal origin by way of their proliferative ability, immunosuppressive properties, and therapeutic efficacy; the use of Wharton's jelly, the primitive connective tissue of the human umbilical cord, is a viable alternate perinatal source of MSCs $[8,9]$.

Induction of the mesoderm to the cardiovascular cell lineages is coordinated by the effectors of the Wnt/ $\beta$-catenin signaling pathway [10] and transforming growth factor-beta superfamily [11]. The role of epigenetic remodeling in cardiac differentiation has been revealed by mutations in chromatin modifiers such as ATPdependent chromatin remodeling complex (CHD7) [12], Williams syndrome transcription factor (WSTF) [13], and histone H3K36 methyltransferase Wolf-Hirschhorn syndrome candidate 1 (WHSC1) [14] —all of which are also involved in the pathogenesis of human heart diseases [15]. Although several epigenetic modifiers have been used in cardiac differentiation, the differentiation efficacy of the clinically relevant MSCs to cardiomyocytes remains poor. Furthermore, little is known about how Wnt mediators and antagonists are regulated by epigenetic modifications to drive cardiomyogenesis.

In this study, we investigate the effect of inhibitors of two main epigenetic processes, DNA methylation and histone deacetylation, on cardiomyogenesis from Wharton's jelly MSCs (WJMSCs), through functional cardiac assays and in-vivo engraftment of derived cardiomyocytes, and reveal an epigenetic remodeling of Wnt antagonists during cardiac differentiation.

\section{Methods \\ Isolation and expansion of WJMSCS}

All study procedures were approved by the Institutional Ethical Committee (IEC) of Manipal Hospital, Bangalore, India. After obtaining informed consent, fresh human umbilical cords $(n=20)$ were obtained and stored in Dulbecco's phosphate-buffered saline (DPBS; Invitrogen, Carlsbad, CA, USA), containing antibacterial and antimycotic agents, prior to tissue processing. Isolation of WJMSCs by enzymatic digestion was performed according to the method of Wang et al. [16] with some modifications. The cord was cut into pieces of $4-5 \mathrm{~cm}$ and, after removal of blood vessels, the Wharton's jelly was scraped off and was washed three to five times with sterile DPBS. Next, the tissue was subjected to enzymatic digestion with $0.2 \mathrm{~g} / \mathrm{ml}$ of collagenase (Sigma-Aldrich, St. Louis, MO, USA) for $16 \mathrm{~h}$ at $37^{\circ} \mathrm{C}$. The digestion was neutralized by adding equal volumes of medium with $10 \%$ fetal bovine serum (FBS; Hyclone, USA), filtered through a $100-\mu \mathrm{m}$ cell strainer (BD Biosciences), and pelleted at $1500 \mathrm{rpm}$ for $10 \mathrm{~min}$. Finally, cells were washed and cultured in growth medium (DMEM-HG) supplemented with penicillin $(100 \mathrm{U} / \mathrm{ml})$, streptomycin $(100 \mu \mathrm{g} / \mathrm{ml})$, and $10 \% \mathrm{FBS}$, and incubated at $37^{\circ} \mathrm{C}$ with $5 \% \mathrm{CO}_{2}$. Cells were first passaged, after 8-10 days, until the formation of colony-forming units and then after every 3-4 days. When confluency was achieved, cells were recovered using $0.25 \%$ Trypsin-EDTA and passaged further. WJMSCs at passage 3 were used for flow cytometric analysis, differentiation, and further analysis in this study.

\section{Characterization of WJMSCs}

At the third passage, WJMSCs were characterized for bona-fide MSC markers by flow cytometry, RT-PCR, and immunocytochemistry 


\section{Trilineage differentiation}

At the third passage, WJMSCs were induced to differentiate into the defining tri-lineages of MSCs; namely osteogenic, adipogenic, and chondrogenic lineages using the protocols that we have previously reported [17, 18].

\section{Differentiation of WJMSCS into cardiogenic lineage}

WJMSCs were grown to $100 \%$ confluence on $0.2 \%$ gelatin coated plates and then subjected to individual or a cocktail of proprietary inhibitors, DC301 (8 $\mu \mathrm{M}$, a DNA methyltransferase 1 (DNMT1) specific inhibitor), DC302 (300 nM) and DC303 $(0.5 \mu \mathrm{M})$, both of which are specific histone deacetylase 1 (HDAC1) inhibitors, and various combinations of these inhibitors (DC301+ DC302, DC301 + DC303, and DC302 + DC303)-for $48 \mathrm{~h}$ in DMEM-HG growth medium containing 5\% FBS. After $48 \mathrm{~h}$, the induction medium was replenished and incubated for a further $24 \mathrm{~h}$, after which the induction medium was replaced with DMEM-HG growth medium containing $5 \% \mathrm{FBS}$, and maintained at $37{ }^{\circ} \mathrm{C}$ with $5 \%$ $\mathrm{CO}_{2}$ and $95 \%$ air for up to 2 weeks. Cardiac progenitors (CP) obtained within 5-7 days and differentiated cardiomyocytes obtained within 10-12 days were used for further experiments.

\section{Immunocytochemistry}

WJMSCs from passage 3 or differentiated cardiomyocytes were grown in chamber slides and fixed using $4 \%$ paraformaldehyde for $20 \mathrm{~min}$ at $4{ }^{\circ} \mathrm{C}$, and were blocked with $3 \%$ bovine serum albumin (BSA) in PBS for $30 \mathrm{~min}$ at room temperature. The cells were then incubated for $1 \mathrm{~h}$ in dark conditions at $4{ }^{\circ} \mathrm{C}$ with primary nonlabeled mouse anti-human antibodies against vimentin (1:500 dilution), GATA4 (1:500 dilution), cardiac actin (1:500 dilution), troponin $\mathrm{I}$ (TnI) (1:500 dilution), troponin $\mathrm{T}$ (TnT) (1:500 dilution), desmin (1:500 dilution), and atrial natriuretic peptide (ANP) (1:500 dilution; all antibodies purchased from BD Biosciences, San Diego, CA, USA) followed by anti-mouse goat fluorescein isothiocyanate (FITC)-labeled secondary antibody (1:1000 dilution; Invitrogen) or anti-rabbit goat phycoerythrin (PE)-labeled secondary antibody (1:1000 dilution; Invitrogen) for $1 \mathrm{~h}$ at $37^{\circ} \mathrm{C}$. An additional step was included for staining the intracellular, nuclear, or cytoskeletal markers (vimentin, cardiac actin, TnI, TnT, desmin, and ANP) by washing the cells with PBS containing $0.05 \%$ Tween-20, along with the treatment of cells using $3 \%$ BSA containing $0.1 \%$ Triton $\mathrm{X}-100$ for $30 \mathrm{~min}$ at room temperature to ensure that cell permeability was achieved. Nuclei were counter-stained with 4',6-diamidoino-2-phenylindole (DAPI) (1:10,000 dilution) for $45 \mathrm{sec}$, and a drop of anti-fade (Vectashield; Vector Laboratory, Burlingame CA, USA) was added to avoid quenching of the fluorochrome. The slides were examined under a Nikon Eclipse TE2000-U fluorescent microscope and images were taken using Qimaging QICAM-fast 1394 (Surrey, BC, Canada).

\section{Flow cytometry}

WJMSCs from passage 3 or differentiated cardiomyocytes were washed with PBS-Tween buffer (PBST) and fixed in prechilled $70 \%$ ethanol. WJMSCs were incubated in mouse anti-human FITC-labeled antibodies against CD73, CD90, CD105, or CD34 (1:100 dilution; all antibodies purchased from Becton Dickinson, San Diego, CA, USA) for $1 \mathrm{~h}$ on ice. Differentiated cardiomyocytes were incubated with unlabeled primary anti-human mouse troponin I antibody (1:100 dilution; BD Biosciences) for $1 \mathrm{~h}$ on ice. After washing with PBST buffer, the differentiated cardiomyocytes were incubated for $30 \mathrm{~min}$ with anti-mouse rabbit FITC-labeled secondary antibodies (Invitrogen). The cells were acquired using a BD-FACS Calibur flow cytometer with a 488-nm laser, and data were analyzed by Cell Quest Software (Becton Dickinson, San Jose, CA, USA).

\section{Semi-quantitative reverse-transcription PCR}

Total RNA was extracted from untreated WJMSCs and WJMSCs treated with epigenetic modifiers, using the RNeasy Plus Mini kit (Queen) according to the manufacturer's instructions. One microgram of total RNA was reverse-transcribed using the SuperScript III First-Strand Synthesis System (Invitrogen). One microgram of total RNA was mixed with $1 \mu$ l Oligo dT $(50 \mu \mathrm{M})$ and $1 \mu \mathrm{l}$ of dNTP $(10 \mathrm{mM})$, and made up to $13 \mu \mathrm{l}$ with DEPCtreated water and heated at $65{ }^{\circ} \mathrm{C}$ for $10 \mathrm{~min}$, followed by incubation on ice. After primer hybridization, a $7 \mu \mathrm{l}$ reaction volume containing $5 \times$ first-strand buffer, RNase OUT $(40 \mathrm{U} / \mu \mathrm{l}), 0.1 \mathrm{M}$ DTT, and Superscript III was added to the RNA and subjected to thermocycling (25 C, $5 \mathrm{~min} ; 50{ }^{\circ} \mathrm{C}, 60 \mathrm{~min} ; 70{ }^{\circ} \mathrm{C}, 15 \mathrm{~min}$ ) in a Veriti 96well thermal cycler (Applied Biosystems). Qualitative expression of cardiac-specific markers-GATA4, Nkx2.5, myosin light chain $(M L C)$, TnT, cardiac actin, ANP, sFRP1-5, Dkk 1 and 3, CreB, calcineurin (CalN), vinculin $(V c l), D D X 20$, and glyceraldehyde 3-phosphate dehydrogenase (GAPDH) (primers were from Sigma, sequence as indicated in Additional file 1: Table S1, S2) - were analyzed by PCR $\left(95{ }^{\circ} \mathrm{C}, 30 \mathrm{~s}\right.$; annealing temperature, $30 \mathrm{~s}$; $72{ }^{\circ} \mathrm{C}, 30 \mathrm{~s}$ for 40 cycles) in a Veriti 96-well thermal cycler. Products were separated by $1.5 \%$ agarose gel electrophoresis and detected using ethidium bromide. Integrated density values (IDV) were calculated using Alpha Manager (San Jose, CA, USA). 


\section{Real-time quantitative reverse-transcription PCR}

The qualitative results of mRNA expression were further quantified using iQ SYBR Green Supermix (Bio-Rad, Hercules, CA, USA) in a real-time PCR system. cDNAs and gene-specific primers were mixed with $2 \times$ iQ SYBR Green Supermix (Bio-Rad), and dispensed on a MicroAmp ${ }^{\oplus}$ Optical 8-Tube Strip. Fluorescence shift was observed using a 7500 Real-time PCR system (Applied Biosystems, Carlsbad, CA, USA). Reaction parameters were $50{ }^{\circ} \mathrm{C}$ for $2 \mathrm{~min}, 95{ }^{\circ} \mathrm{C}$ for $10 \mathrm{~min}$, followed by 40 cycles of $95{ }^{\circ} \mathrm{C}$ for $15 \mathrm{~s}$ and $60{ }^{\circ} \mathrm{C}$ for $1 \mathrm{~min}$. The genes Sox2, Oct4, CD44, CD34, and Nanog were analyzed from cDNA obtained from WJMSCs for stemness and pluripotency traits. WJMSCs treated with epigenetic modifiers were analyzed for cardiac-specific genes cardiac actin, GATA4, Nkx2.5, MLC, TnT, and ANP, and for noncardiac markers such as PPARY for adipocytes, collagen II for chondrocytes, and osterix for osteocytes. Wntrelated and other genes that were studied were $S F R P 1-5$, Dkk 1 and 3, CreB, CalN, $\mathrm{Vcl}$, and DDX2O (primers are from Sigma Aldrich, sequence as indicated in Additional file 1: Table S1, S2, and S3). The relative abundance of mRNAs was obtained using the comparative cycle threshold method and was normalized to the housekeeping control GAPDH. Results were also expressed as fold changes in the mRNA levels of a gene compared to the treated or untreated samples.

\section{Determination of intracellular calcium release}

The increase in intracellular calcium levels after cardiac differentiation of WJMSCs was determined using the fluorescent radiometric $\mathrm{Ca}^{2+}$ indicator Fura-2 acetoxymethyl ester (Fura-2, $1 \mu \mathrm{mol} / \mathrm{L}$; Molecular Probes, Invitrogen, Carlsbad, CA, USA) as reported previously [19]. After induction of WJMSCs with DC301 + DC302 as described, the cells were washed and Fura-2 (1 $\mu \mathrm{mol} / \mathrm{L}$; Molecular Probes) was added to the cells in plain medium and incubated for $37{ }^{\circ} \mathrm{C}$ for $45 \mathrm{~min}$. Fluorescent intracellular $\mathrm{Ca}^{2+}$ flux was identified by fluorescence microscopy (450-480 nm) and calorimetrically at $480 \mathrm{~nm}$.

\section{Nitric oxide release assay (Greiss assay)}

A modified Griess reagent kit (Sigma Aldrich) was used to detect nitric oxide (NO) release after cardiac differentiation. After WJMSCs were induced to differentiate with various combinations of epigenetic modifiers as described previously, an equal number of cells were plated in 96-well plates with a density of 10,000 cells/well. After $24 \mathrm{~h}, 100 \mu \mathrm{l}$ of Griess reagent was added to each well and incubated for 15-20 min in a dark room, and absorbance was measured at $540 \mathrm{~nm}$ using a Victor $3 \mathrm{Mul}$ tilabel Plate Reader (Perkin-Elmer, Waltham, MA, USA).
Bisulfite modifications and methyl-specific PCR

Genomic DNA was extracted from WJMSCs and differentiated cardiomyocytes using the phenol-chloroform extraction method. To identify the CpG island methylation status, the DNA was subjected to bisulfite modification using the EpiTect plus DNA bisulfite kit (Qiagen, Venlo, the Netherlands) following the manufacturer's instructions. Methyl and unmethyl specific primers (Additional file 1: Table S4) for Nkx 2.5 and sFRP4 were designed using MethPrimer (The Li Lab Software). Methyl-specific PCR was performed as follows: $95{ }^{\circ} \mathrm{C}$ for $3 \mathrm{~min}, 40$ cycles of $95{ }^{\circ} \mathrm{C}$ for $30 \mathrm{~s}, 55^{\circ} \mathrm{C}$ for $1 \mathrm{~min}, 72{ }^{\circ} \mathrm{C}$ for $1 \mathrm{~min}$, and $72{ }^{\circ} \mathrm{C}$ for $7 \mathrm{~min}$. The product was loaded on a $2 \%$ agarose gel and bands observed under an UV illuminator and imaged using Alpha Imager (San Jose, CA, USA).

\section{Bisulfite sequencing}

Bisulfite-converted DNA from WJMSCs and differentiated cardiomyocytes was amplified using bisulfitespecific primers for the promoter regions of $N k x 2.5$ and sFRP4. The amplicons were then scaled up by bulk PCR, and the eluted products (extracted using the QIAquick gel extraction kit; Qiagen) were sequenced by Sanger's sequencing following a standard protocol [20]. The results comparing the methylation status were analyzed using BiQ Analyzer, a software tool for DNA methylation analysis.

\section{In-vivo model of cardiac injury and cellular transplantation}

In order to study the effect of untreated and treated WJMSCs in a cardiac injury model, cardiac damage was induced in male C57BL/6 mice following the protocol of Desai et al. [21] with some modifications. All animal experiments were performed at Anthem Biosciences Ltd (Bangalore, India) after approval by the Institutional Animal Ethics Committee. Male C57BL/6 mice (25-30 g body weight, $n=4$ ) aged $10-12$ weeks were used to create an in-vivo model for cardiac damage, induced by intraperitoneal injection of $2.5 \mathrm{mg}$ doxorubicin (dox) $/ \mathrm{kg}$ body weight, thrice weekly for 2 weeks. Control animals $(n=4)$ were injected intraperitoneally with normal saline ( $5 \mathrm{ml} / \mathrm{kg}$ body weight). Cardiac fibrosis was assessed by staining sections of the heart with hematoxylin and eosin (H\&E) and Masson's trichrome.

After detection of cardiac damage by dox, the mice were injected with either untreated WJMSCs or with CP, which were ascertained to be positive for troponin I by flow cytometry. Control animals received DMEM medium on day 0 , after dox treatment. WJMSCs or CP $\left(1 \times 10^{6}\right.$ cells of each type/animal, $\left.n=4\right)$ were administered as a single dose intravenously on day 0 , after dox treatment. Prior to injection, the cells (WJMSCs and 
$\mathrm{CP})$ were fluorescently labeled with CellTracker ${ }^{\mathrm{ma}}$ probe (1:1000 dilution; Invitrogen) by incubating for $15 \mathrm{~min}$ and washing with medium. The body weight was measured every alternate day. Animals were sacrificed after 18 days by $\mathrm{CO}_{2}$ asphyxiation. The heart was excised, observed for necrosis, and then either fixed in $10 \%$ formalin for sectioning or stored in TRIZOL for gene analysis.

\section{Histological analysis}

After the animals were sacrificed, sections of the heart $(5 \mu \mathrm{M})$ were generated using standard histological techniques. Paraffin sections were prepared from Bouin's fixed samples using standard procedures [22]. H\&E and Masson's trichrome staining were all performed according to the manufacturer's instructions (Sigma Diagnostics, St Louis, MO, USA). Slides were examined under a brightfield phase-contrast microscope (Nikon-Eclipse TE 2000-S) and images were taken using Qimaging QICAM-fast 1394. (Surrey, BC, Canada). Fibrotic areas and tissue architecture were analyzed in H\&E sections, and fibrosis and collagen content was examined using Masson's trichrome staining.

\section{Statistical analysis}

All data were represented as mean and SE obtained from experiments performed in triplicate. Statistical significance was assessed by the Student's unpaired $t$ test. For all statistical analyses, $p<0.05$ was considered significant.

\section{Results}

\section{Isolation and characterization of WJMSCs}

After isolating WJMSCs, we first characterized them for MSC-like properties, as shown in Additional file 2: Figure S1. First, we observed cells from colony-forming units forming a homogeneous mat of cells (Additional file 2: Figure S1A1), which were positive for the typical MSC marker, vimentin, by immunohistochemistry (Additional file 2: Figure S1A2). We then characterized for the gene expression of pluripotency markers such as Sox2, Oct4, and Nanog, and for the MSC positive CD marker CD44 and negative marker CD34, and found that Oct 4, Nanog, and CD44 were highly expressed whereas CD34 expression was minimal (Additional file 2: Figure S1A3). Flow cytometric analyses of WJMSCs revealed the presence of characteristic $\mathrm{CD}$ markers, CD73 (90.84\%), CD90 (90.91\%), and CD105 (88.77\%), and only $3 \%$ were CD34 positive (Additional file 2: Figure S1B). Final confirmation of the MSC-like phenotype of this cell population was achieved by their ability to differentiate into the trimesodermal lineages, namely adipocytes (Additional file 2: Figure S1C1), osteocytes (Additional file 2: Figure S1C2), and chondrocytes (Additional file 2: Figure S1C3).

\section{Differentiation of WJMSCs with various epigenetic modifiers}

After isolation and characterization of human WJMSCs from the umbilical cord (Additional file 2: Figure S1), we subjected WJMSCs (passage 3) to various epigenetic modifiers; namely the specific DNMT1 inhibitor DC301, the HDAC1 inhibitors DC302 and DC303, and various combinations of these markers. After induction for $24 \mathrm{~h}$ and incubation for 9 days, we observed differentiation with a change in morphology into a cardiomyocyte phenotype, seen best in the MSCs treated with DC301 and DC302 (Fig. 1a). We next analyzed the expression of early (Nkx2.5, GATA4) and late (MLC, TnT, cardiac actin) cardiac markers in MSCs differentiated by various combinations of epigenetic modifiers using quantitative RT-PCR (Fig. 1b). We observed that, although there was an increase in the expression of cardiac genes in all of the conditions tested, the expression was much higher in MSCs treated with DC301 and DC302. Therefore, we used MSCs treated with DC301 + DC302 for most of the further downstream studies.

\section{Functional characterization of MSC-derived cardiomyocytes}

To confirm the identity of these differentiated cardiomyocytes, we analyzed the cells for characteristic functional cardiac proteins. Using immunocytochemistry, cardiac actin, TnI, TnT, desmin, and ANP were seen to localize as cytoplasmic striations. GATA4, an early transcription factor, was seen to localize in the nuclear region (Fig. 1c). In addition, three noncardiac lineages (ostoegenic, chondrogenic, and adipogenic) and their respective specific markers, osterix, collagen II, and PPAR $\gamma$, were examined after treatment of WJMSCs with DC301 + DC302. We observed lack of expression of these specific markers, confirming that DC301 + DC302 (Fig. 1d) treatment did not promote differentiation into these lineages. Next, we analyzed the total population of differentiated cardiomyocytes using the differentiated cardiomycyte marker TnI by flow cytometry. It was observed that $77 \%$ of the population was positive for TnI, indicating the efficiency of cardiomyocyte differentiation after treatment of WJMSCs with DC301 + DC302 (Fig. 1e).

\section{Analysis of Wnt antagonists in MSC-derived cardiomyo- cytes revealed upregulation of sFRP4 and Dkk1 and Dkk3} Based on reports of Wnt antagonism in cardiac differentiation [23, 24], we analyzed the expression of Wnt antagonists of the secreted frizzled-related protein (sFRP) family, sFRP1-5, and the Dickkopf (Dkk) family, Dkk 1 and 3. Although sFRP1, sFRP2, and sFRP4 have been implicated in cardiomyogenesis and ischemic repair [25-27], the expression profile of the sFRP family during cardiac 


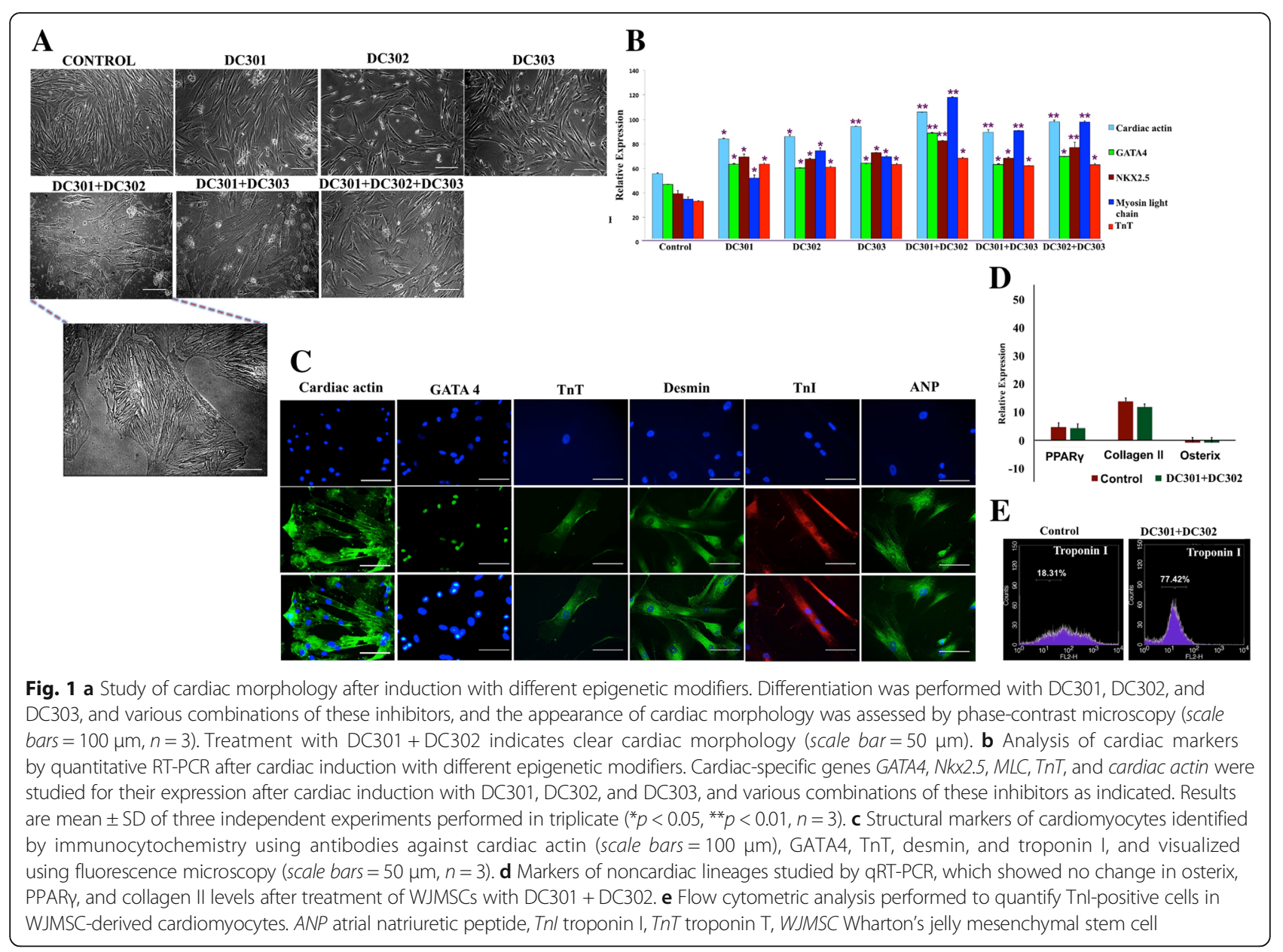

differentiation from MSCs has not been studied. We found that among $S F R P 1-5$, expression of $S F R P 4$ was the most prominent during cardiac differentiation from WJMSCs (Fig. 2aA1). There was also a concomitant increase in the expression of $D k k 1$ and $D k k 3$ (Fig. 2aA2).

\section{Wnt-related genes and structural genes were upregulated} during cardiomyogenesis

$\mathrm{CreB}$ and $\mathrm{CalN}$, which belong to the $\mathrm{Wnt} / \mathrm{Ca}^{2+}$ signaling pathway, were examined for their mRNA expression levels, and we found that both were expressed more in the treated cells than in the undifferentiated control. We also analyzed the expression of $V C L$, a Wnt-related structural gene that has been implicated in preserving cardiomyocytes from aging [28]. Vinculin expression was higher in differentiated cardiomyocytes than in undifferentiated control MSCs (Fig. 2bB1, B2). DDX20, an RNA helicase, was another gene that was analyzed. DDX20, or DEAD-box protein 103, which is essential for early embryonic development, has been known to indirectly interact with GATA4 [29]. On examination of the expression of $D D X 20$, we found it to be highly overexpressed in differentiated cardiomyocytes (Fig. 2bB1, B2).

\section{Calcium release was observed in MSC-derived cardiomyocytes}

Intracellular $\mathrm{Ca}^{2+}$ transients regulating excitation and contraction are an important event accompanying successful differentiation into cardiomyocytes [30]. Using a calciumsensitive dye, FURA2M, we observed clear intracellular localization of $\mathrm{Ca}^{2+}$ in only differentiated cardiomyocytes and not in the untreated MSCs. There was a prominent cytoplasmic localization of $\mathrm{Ca}^{2+}$, suggesting that the cardiomyocytes may be primed for contraction (Fig. 2c).

\section{Cardiomyogenesis is accompanied by nitric oxide release}

$\mathrm{NO}$ is an important physiological messenger of cardiac differentiation from embryonic stem cells [31]. NO is a diffusible free radical and signaling molecule, which has an important role in controlling the heart rate, contractibility, and cardiac development [32]. However, no study has so far ascertained NO levels in cardiomyocytes differentiated from human MSCs. We used the classic Griess reagent for measuring levels of NO in MSCs differentiated to cardiomyocytes using various cocktails. The highest accumulation of NO (twofold over the control) was observed in cardiomyocytes derived from DC301+ 


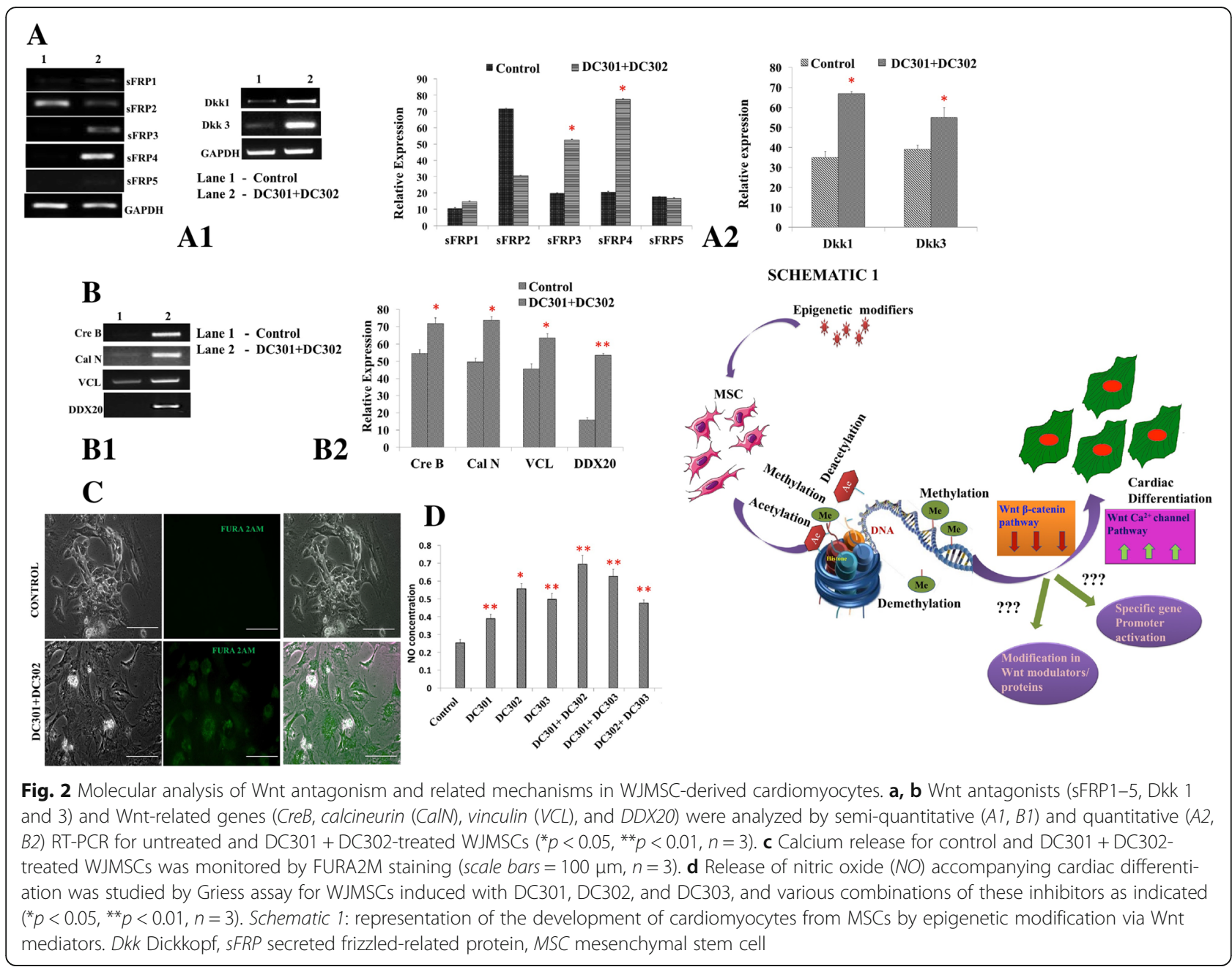

DC302 treatment (Fig. 2d). These results confirmed the functionality of the differentiated cardiomyocytes.

\section{Cardiomyogenesis results in promoter demethylation of Nkx2.5 and sFRP4}

To understand molecular changes in the gene structure accompanying cardiogenesis, we investigated the epigenetic changes in the promoter regions of the early cardiac gene, $N k x 2.5$. To delve deeper into the role of Wnt antagonism in cardiogenesis, we examined whether sFRP4 (which was overexpressed, as seen by quantitative RTPCR studies) was activated by promoter demethylation. The gene structure of $N k \times 2.5$ and sequences of the promoter region are represented in Fig. 3a. After bisulfite conversion of the DNA from untreated MSCs (U) and differentiated cardiomyocytes (D), we amplified $N k x 2.5$ promoter regions and sequenced the products (Fig. $3 \mathrm{~b}$ ). It was seen that after differentiation with DC301 + DC302, 6 out of the $10 \mathrm{CpG}$ islands underwent demethylation in D (Fig. 3c). We could also see clearly that the unmethylated specific primer DNA product was increased in D while the methylated specific DNA product was high in $\mathrm{U}$ (Fig. 3d). Significantly, a remarkable change was observed in the SFRP4 profile after cardiac differentiation. For the first time, we showed that a Wnt antagonist was activated in cardiogenic differentiation from MSCs by promoter demethylation. After alignment of the bisulfite sequences of $U, D$, and genomic DNA, we observed that 7 out of the $26 \mathrm{CpG}$ islands in the $S F R P$ promoter regions underwent demethylation in the cardiac differentiated cells (D) (Fig. 4b, c). The sFRP4 promoter region and the sequences are shown in Fig. 4a. Confirmation of demethylation of CpG in differentiated cells was provided by the presence of unmethylated specific sFRP4 DNA in differentiated cells (Fig. 4d).

\section{In-vivo engraftment and reversal of cardiac damage by MSC-derived cardiomyocytes}

\section{Establishment of cardiac fibrosis in mice by treatment with} doxorubicin

We first established a cardiac injury model in C57BL/6 mice by inducing cardiotoxicity with a known cardiotoxic oncotherapeutic drug, doxorubicin. After injection 


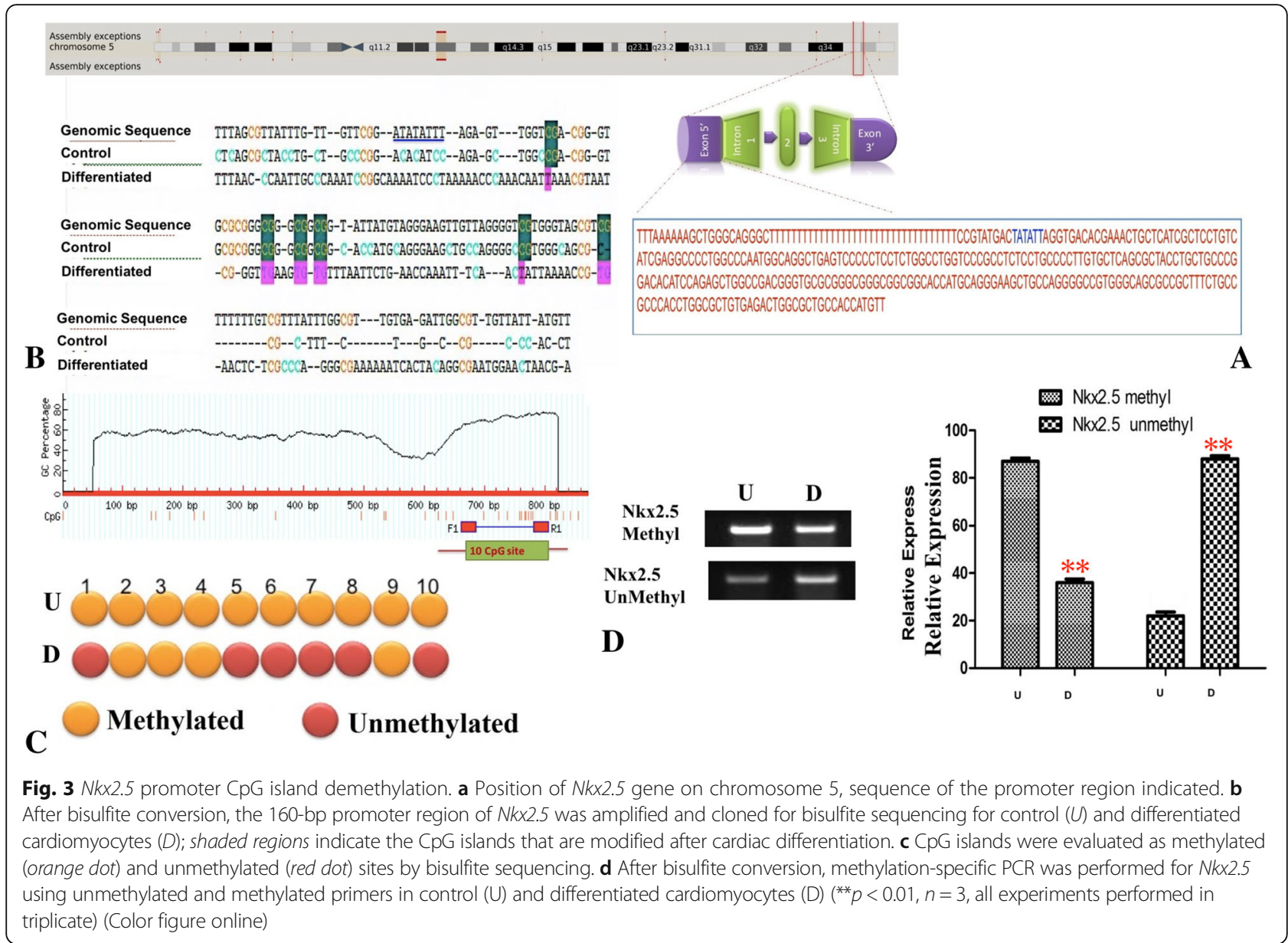

of $2.75 \mathrm{mg}$ doxorubicin/ $\mathrm{kg}$ body weight in six equal injections on alternate days, we examined heart sections by $H \& E$ staining and observed fibrosis in dox-treated mice (Fig. 5b, indicated in the red circle) when compared to the control (Fig. 5a). Masson's trichrome staining revealed increased cardiac fibrosis, as indicated by fibrosis-specific collagen staining (blue) (Fig. 5d) in comparison to medium-treated mice (Fig. 5c). The plan and rationale of the in-vivo studies for the induction of cardiotoxicity by doxorubicin and the engraftment of MSCderived cardiomyocytes for cardiac restoration is depicted schematically (Fig. 5 Schematic 2).

\section{Transplantation of WJMSCs and cardiac progenitors into mice induced with cardiac fibrosis}

After inducing cardiac injury, mice were injected with WJMSCs or CP to study the reversal of cardiac damage, and were compared with mice that received only cellfree medium. Initially, after the dox treatment period, there was a decrease of about $15 \%$ in body weight (Fig. 5e). Body weight was measured every alternate day, post cellular injection. There was a $9 \%$ increase in body weight in CP-injected animals (Fig. 5f). After 18 days post injection, the animals were sacrificed and the necrotic areas of the heart studied. Necrotic areas were slightly reduced in mice that received WJMSCs (Fig. $5 \mathrm{~g}$ ) when compared to the control (Fig. 5g). Significantly, we observed that there was no necrosis in the mice receiving $\mathrm{CP}$ treatment (Fig. 5g).

H\&E staining showed that, when compared to the control medium (Fig. 6aA2), MSC-transplanted mice showed a marked reduction in necrotic areas (Fig. 6aA3). Remarkably, we could see a complete loss of necrosis in CP-treated mice (Fig. 6aA4), with tissue architecture similar to the untreated normal mouse heart (Fig. 6aA1).

\section{Engraftment of WJMSCs and cardiac progenitors, and formation of functional cardiomyocytes}

To establish homing and engraftment of MSCs and CPs to the site of injury, we labeled cells with a red fluorescent cell tracker and found that mice injected with both MSCs and CPs showed fluorescence in the cardiac sections. In CP-treated mice, there was a visible decrease in the size of the fibrotic region and homing cluster (as indicated by the arrow at higher resolution) compared to MSC-treated mice (Fig. 6b). We established the gene 


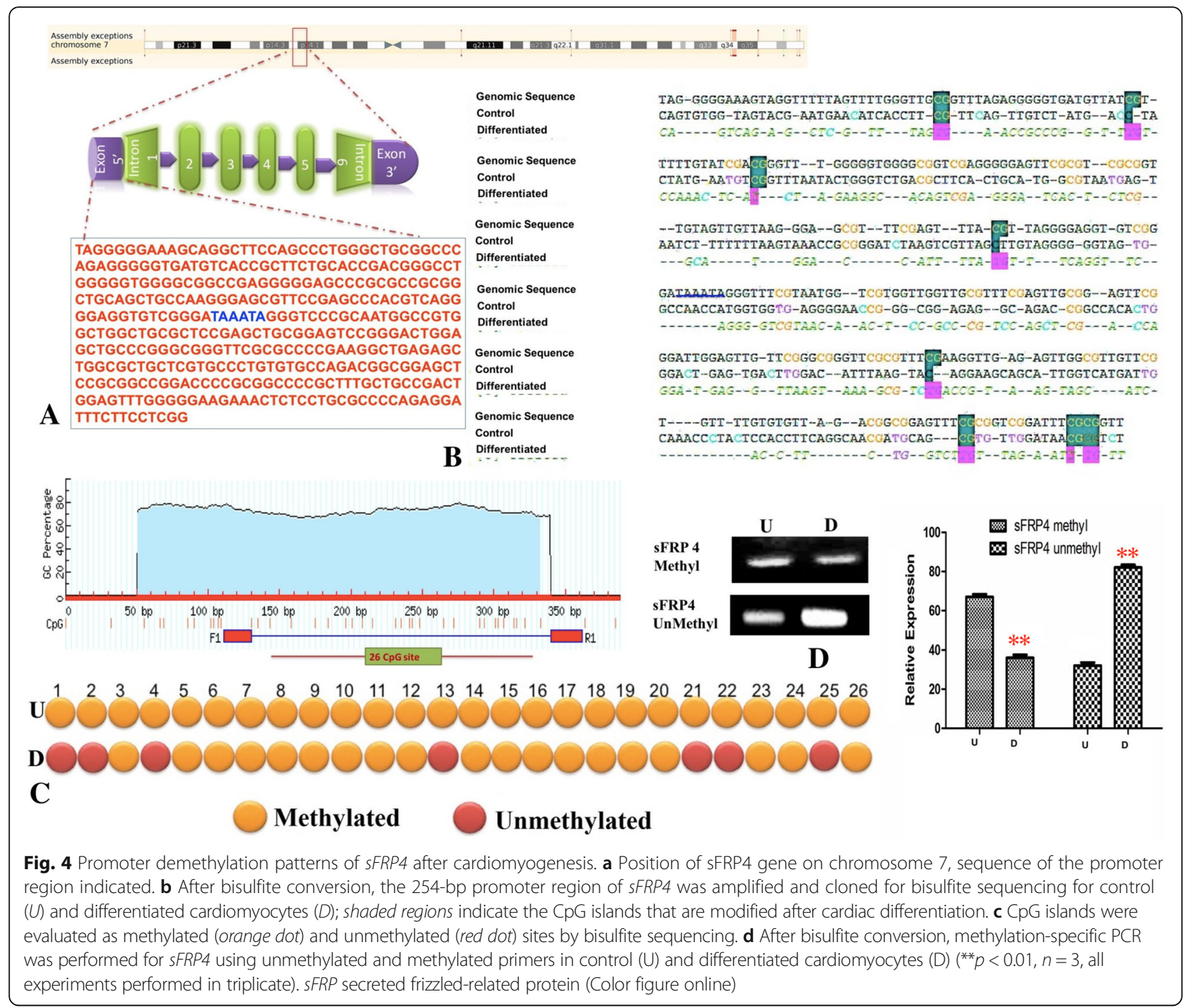

expression of cardiac markers $A N P, M L C$, and $T n T$ by quantitative RT-PCR. It was clearly seen that MSCtreated and CP-treated mice had higher expression of these genes compared to the Dox-treated mice, and CPtreated mice had the highest fold expression, showing nearly complete recovery of cardiac functional gene expression (Fig. 6c).

\section{Discussion}

The regulation of expression of transcription factors during cardiogenesis is orchestrated by epigenetic changes that establish and maintain the expression of cardiac-specific genes. This study demonstrates the robust derivation of functional cardiomyocytes from WJMSCs using a combination of epigenetic modifiers. Major epigenetic reprogramming events associated with cardiogenesis are DNA methylation and histone acetylation [33]. A combination of inhibitors of DNA methylation and histone deacetylation has been used for the first time in our study to successfully derive cardiomyocytes from human WJMSCs. These chromatin remodelers initiated dynamic changes in the chromatin structure and possibly resulted in promoter accessibility of some genes, such as early stage cardiac transcription factors, $N k \times 2.5$ and GATA4, and the masking of other noncardiac and self-renewal genes.

Specification of these presumptive cardiogenic cells begins with the induction of the early transcription factor, Nkx2-5, regulated by Cerberus and possibly BMP2 $[34,35]$. Nkx2-5 is a key protein guiding the mesoderm to become heart by initiating the synthesis of other cardiac transcription factors such as GATA4 and MEF2C. These transcription factors, in turn, upregulate cardiomyocyte-specific proteins such as cardiac actin, atrial natriuretic factor, and alpha myosin heavy chain [36]. Early cardiac differentiation is marked by a change 


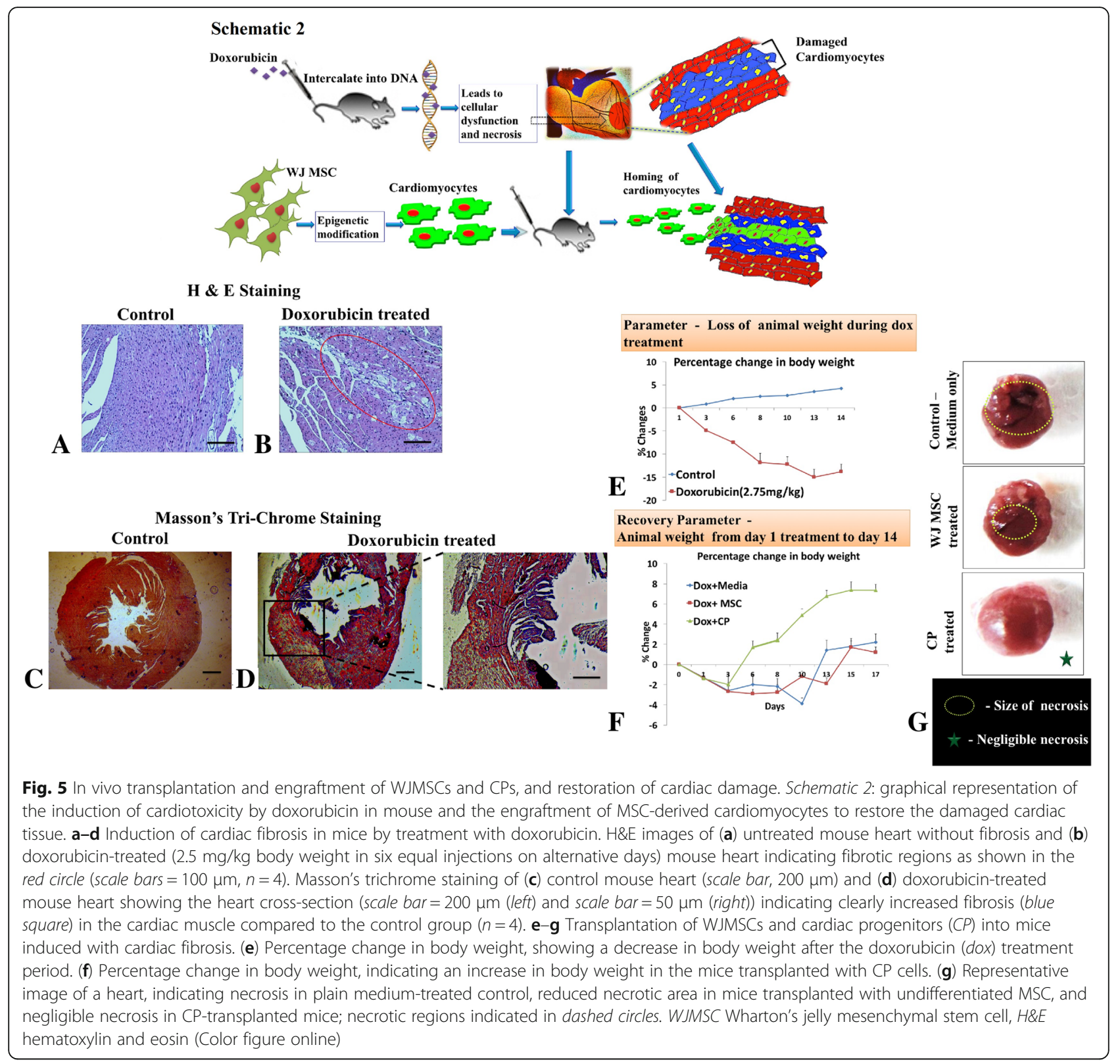

in the epigenetic landscape appropriate for cardiogenesis, including activation of cardiac-specific genes and repression of cell cycle progression genes and noncardiac genes [37]. Epigenetic modifications include covalent posttranslational modifications of either the DNA or the nucleosomes tightly regulated by specific enzymes; the main enzymes being DNA methyltransferases and histone deacetylases [38]. These enzymes block access to the promoter and histone regions, thereby gridlocking active transcription of the downstream genes. Suppression of $H D A C 1$ has shown to promote cardiogenesis by upregulating $N k x 2.5$ [39]. Likewise, DNA demethylation of the $\mathrm{CpG}$ islands of the promoter regions of Nkx2.5 and GATA4 clears the path to access these promoters for active transcription. In our study, we used a combination of inhibitors of these enzymes and found that this efficiently generates cardiomyocytes. Therefore, our strategy has probably aided in an unlocking of the cardiac-specific promoters to drive active cardiomyogenesis. A schematic overview of the use of epigenetic modifiers for the development of cardiomyocytes from MSCs is represented in Fig. 2 (Schematic 1).

In the embryonic heart, Wnt signaling is one of the key modulators of cardiac development. The role of Wnt is also prominently evident upon pathological stress requiring adult heart remodeling. Blockage of Wnt signaling via Dkk has shown to significantly increase cardiac progenitors in embryonic stem cells [40]. Among 


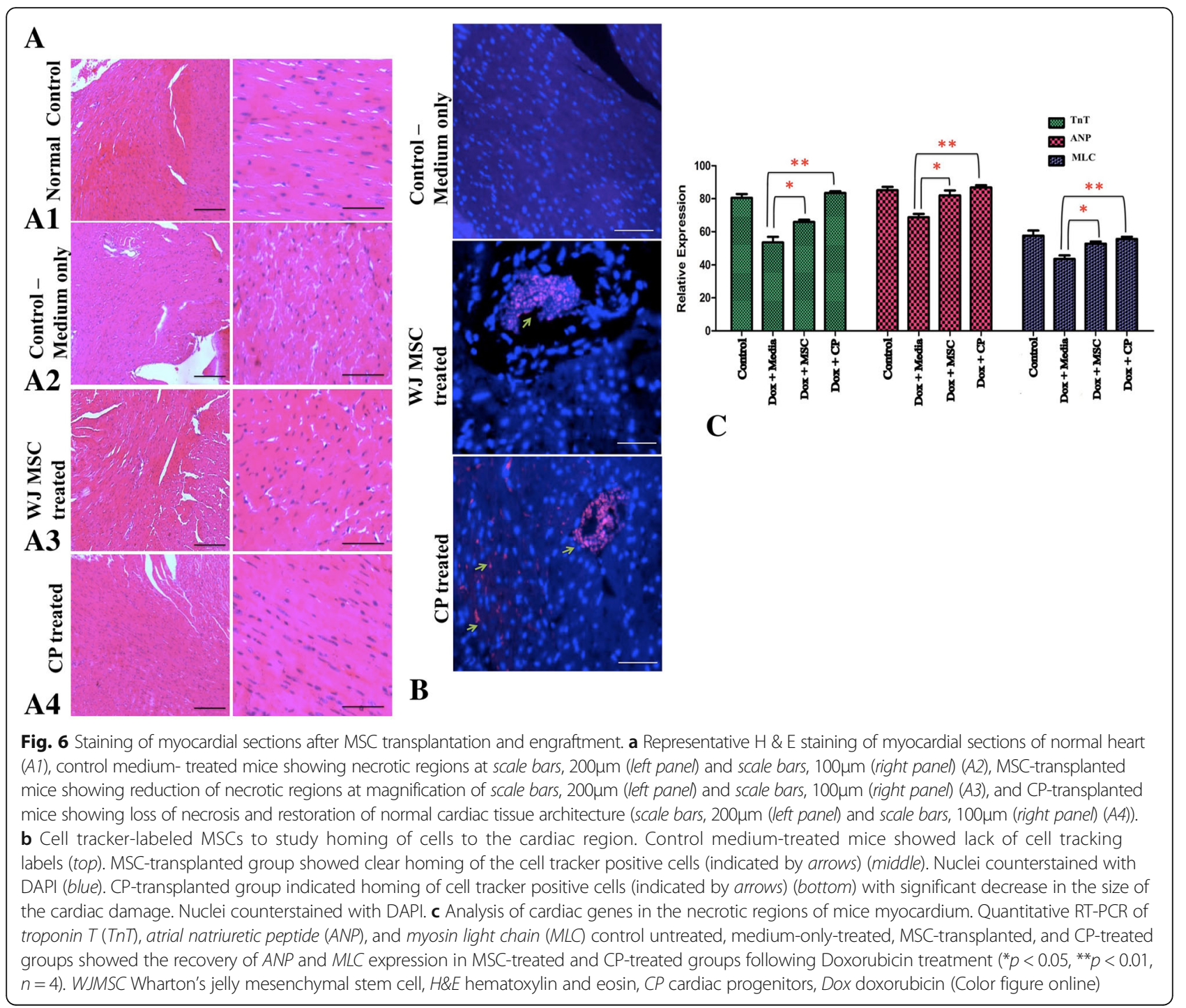

the sFRPs studied, sFRP1 has a role in cardiac differentiation in Xenopus by promoting cardiac differentiation and regulating the normal heart size and cell fate within the cardiac mesoderm [41], and sFRP1-overexpressing mice showed reduced infarct size [42]. A positive role of canonical Wnt signaling has been reported in early cardiogenesis, followed by Wnt antagonism being more functional in later cardiac-specific gene expression [43]. In differentiated cardiomyocytes, we observed a clear effect of Wnt antagonism by an elevated expression of sFRP4 and a parallel increase of Dkk1 and Dkk3. Although the exact mechanism of activation is not yet known, we could observe epigenetic demethylation of sFRP4 promoter regions. One of the functions of sFRP4 overexpression would be to direct cells to exit the cell cycle and also inhibit proliferation of the differentiated cells. This would be similar to the effect of sFRP4 in glioma and head and neck cancers, where we demonstrated that it downregulates the proproliferation genes cyclin D1 and c-myc [44, 45].

The Wnt noncanonical pathway, functioning independent of $\beta$-catenin, branches into the $\mathrm{Wnt} / \mathrm{JNK}$ and Wnt $/ \mathrm{Ca}^{2+}$ pathways, the latter route involving a release of intracellular calcium ions. This results in the activation of calcium-sensitive enzymes such as protein kinase $\mathrm{C}$ (PKC), calcium/calmodulin-dependent kinase (CaMK) II, or calcineurin. The noncanonical Wnt pathway is considered to inhibit canonical Wnt signaling [46], which could explain the expression of canonical Wnt antagonists and the activation of noncanonical Wnt/ $/ \mathrm{Ca}^{2+}$ mediators seen in the present study. Expression of calcinuerin and its downstream mediators, such as the nuclear transcription factor $\mathrm{CreB}$, indicates a clear initiation of the $\mathrm{Wnt} / \mathrm{Ca}^{2+}$ axis. The accumulation of intracellular calcium in differentiated cardiomyocytes corroborates a definite involvement of the $\mathrm{Wnt} / \mathrm{Ca}^{2+}$ 
pathway in cardiomyogenesis. Recently, a structural gene along the Wnt pathway, vinculin, has been reported to stave off aging of the heart [28]. Vinculin enhances the contractile function and hemodynamic stress tolerance of the heart by improving intercardiomyocyte connections and enhancing myofilament organization. The vinculin expressing differentiated cardiomyocytes obtained in our study could be an ideal cell type for cardiac muscle transplantation and restoration. Another gene that we found overexpressed in the differentiated cardimyocytes is DDX20, which belongs to the DEAD-box family of RNA helicases. DDX20 assembles a corepressor complex with ETS, which functionally interacts with the E2F/pRB family of proteins inhibiting proliferation. This complex then directs a permanent cell cycle exit during terminal differentiation [47].

Nitric oxide is a pleiotropic signaling molecule acting as a vasoactive agent, neurotransmitter, and a free radical in mammalian systems. Accompanying cardiogenesis, we could clearly see a release of NO, which is the first time to our knowledge that $\mathrm{NO}$ release has been documented in cardiomyogenesis from human MSCs. $\mathrm{NO}$ activates class IIa HDACs and histone deacetylation in endothelial cells, and modulates mesodermal commitment in embryonic stem cells [48]. Exposure to NO donors enhanced the expression of Nkx2.5 and myosin light chain (MLC2) in human ESCs via cGMP signaling [49] The classic mode of action of NO is via the activation of guanylate cyclase [49]. Mujoo et al. reported that the expression of various subunits of soluble guanylyl cyclase (sGC alpha and beta 1 and 2) and nitric oxide synthase(s) (NOS-1, NOS-2, NOS-3) increased in cardiac differentiated cells compared to undifferentiated $\mathrm{H}$ 9 embryonic stem cells [49]. This pathway could be operational in our present model of cardiomyocyte differentiation from WJMSCs.

Next, we analyzed the gene promoter methylation status and found that not only $N k \times 2.5$ underwent promoter demethylation but also $S F R P 4$, which revealed a demethylation at 7 of its $26 \mathrm{CpG}$ islands, and could be one of the reasons for its activation. Lineage commitment genes in naïve stem cells are maintained in a repressed state by specific patterns of histone acetylation and methylation, and DNA promoter methylation at the CpG islands [50]. In the present study, induction of cardiac lineage differentiation by epigenetic modifiers was coupled by the activation of Wnt antagonists. This is the first report, to our knowledge, giving a glimpse into the role of promoter demethylation in sFRP activation. Furthermore, even partial demethylation of the sFRP4 promoter, as observed in this study, was sufficient to elicit the cardiogenic phenotype. Wnt inhibition is considered essential to allocate the cardiac progenitors into various cardiac derivatives [51]. sFRP1, along with Wnt8a, has been shown to be overexpressed in differentiating cardiomyocytes [52]. Silencing of sFRPs has been largely believed to be by promoter region hypermethylation, which represses their tumor-suppressive properties in glioma [53] and acute myeloid leukemia [54]. Epigenetic silencing of sFRPs, by which the tumor seeds are sown, could be the default status in undifferentiated stem cells. Relieving the epigenetic blockage could be the point in early development when crucial decisions of cell fate commitment are determined. Cardiac lineage commitment from undifferentiated stem cells could thus be favored by the CpG promoter demethylation of $s F R P 4$, as observed in our study. MSCs showing promoter demethylation of $N k \times 2.5$ upon cardiomyogenesis has so far been reported only for cardiac MSCs [55]. These MSCs displayed changes at the promoter regions of early cardiac genes (including $N k x 2.5)$ upon cardiac induction with an epigenetic cocktail. Our observation of CpG demethylation of the promoter region upstream of $N k x 2.5$, studied for the first time in the context of cardiac differentiation from WJMSCs, is in agreement with reports on cardiac MSCs and cardiac differentiation from ESCs [20].

Doxorubicin has long been known to induce cardiotoxicity and cause damage to cardiomyocytes by binding to topoisomerase $2 \mathrm{~b}$ [56]. Given this effect of doxorubicin, this drug has been exploited for use as a cardiac damage-inducing drug in animal models [57], which we utilized in the present study. We found that cardiomyocytes differentiated in vitro were capable of restoration of cardiac tissue after doxorubicin-induced damage. Importantly, the cardiac progenitors were more efficient in repairing the damaged tissue, increasing the body weight and survival of the animals. There are several possible reasons to explain these findings. The progenitor cells can home easily to the site of injury, secrete paracrine factors, and can differentiate eventually into functional cardiomyocytes to improve cardiac function. Many reports have demonstrated that endogenous cardiac stem/ progenitor cells or bone marrow-derived cells mobilize to the infarcted area after injury and recruit additional cells through a feedback mechanism [58]. It is also possible that the transplanted cardiac progenitor cells mobilize endogenous cardiac stem cells at the site of injury through paracrine secretions. This is in agreement with previous findings showing that 5aza treatment of BMMSCs (bone marrow mesenchymal stem cells) inhibited the ventricular scar from thinning and expanding, and minimized left ventricular chamber dilatation by improving the elasticity and contractility of BMMSCs [59]. Furthermore, the anti-fibrotic effect observed in the present study could be comparable to MSCs that stimulate the secretion of matrix metalloproteases and matrix metalloproteinase endogenous inhibitor, TIMP, by cardiac fibroblasts, as observed in a myocardial ischemic 
model in mice [60]. Overexpression of sFRP4 or Dkk1 by the cardiac primed cells could also function as a paracrine factor in normalizing cardiac function. A similar effect has been reported in MSCs overexpressing Akt or sFRP2, which inhibited adverse remodeling, fibrosis, and cardiomyocyte hypertrophy in a rat infarct model, suggesting a paracrine role for these secreted factors [61].

\section{Conclusion}

We report here an efficient and robust differentiation of functional cardiomyocytes from Wharton's jelly-derived MSCs using a cocktail of epigenetic modifiers, with an active involvement of Wnt mediators. These observations provide new insights into the involvement of Wnt regulators during cardiac differentiation. Priming of MSCs with an epigenetic cocktail may thus represent an efficient strategy for cardiomyocyte repopulation, which would be useful for cell-based therapy.

\section{Additional files}

Additional file 1: Table S1. Presenting cardiac-specific gene primers, Table S2 presenting Wnt-related gene primers, Table S3 presenting stemness and noncardiac gene primers, and Table $\$ 4$ presenting methylation-specific primers. (DOCX $20 \mathrm{~kb}$ )

Additional file 2: Figure S1. Showing characterization of WJMSCs. A1 Photomicrograph of a confluent layer of MSCs obtained from Wharton's jelly (scale bar $=200 \mu \mathrm{m}, n=3$ ). A2 Immunohistochemical staining of WJMSCs with vimentin and nuclei counter-stained with DAPI (scale bar $=100 \mu \mathrm{m}, n=3$ ). A3 Quantitative RT-PCR of MSC marker CD44 and pluripotency markers Oct4, Nanog, and Sox2, and negative CD34 mRNA expression of WJMSCs $\left({ }^{*} p<0.05\right.$, $\left.{ }^{* *} p<0.01, n=3\right)$. B Flow cytometric analysis of WJMSCs for MSC-positive CD markers CD73, CD90, and CD105, and negative marker CD34. C1-C3 Trilineage differentiation of WJMSCs: Oil Red 'O' staining for adipocyte differentiation (C1), Von Kossa staining for osteocyte differentiation (C2), and Alcian Blue staining for chondrocyte differentiation of WJMSCs (C3) (scale bar = $100 \mu \mathrm{m}$, $n=3$ ). (TIFF $9437 \mathrm{~kb}$ )

\section{Abbreviations}

ANP: Atrial natriuretic peptide; CP: Cardiac progenitors; MSC: Mesenchymal stem cell; MSP: Methylation Specific Primers; Tnl: Troponin I; TnT: Troponin T; WJMSC: Wharton's jelly mesenchymal stem cell

\section{Acknowledgements}

This work was supported partly by funding from the Department of Biotechnology, India (No. BT/PR9235/MED/31/258/2014) for SW. GB is thankful for support in the form of a scholarship from Manipal University, India.

\section{Funding}

This work was supported partly by funding from the Department of Biotechnology, India (No. BT/PR9235/MED/31/258/2014) for SW.

\section{Availability of data and materials}

Supplementary data have been provided.

\section{Authors' contributions}

SW conceived and designed the experiments, analyzed the data, contributed reagents/materials/analysis tools, and wrote the manuscript. GB performed the experiments. FA analyzed the data and edited the manuscript. APK contributed reagents/materials/analysis tools and edited the manuscript. AD analyzed the data, contributed reagents/materials/analysis tools, and edited the manuscript. All authors read and approved the final manuscript.

\section{Ethics approval and consent to participate}

Human placental samples were obtained after the approval of Institutional Ethical Committee (IEC) of Manipal Hospital, Bangalore, India and after obtaining informed consent. All animal experiments were performed at Anthem Biosciences Ltd, Bangalore, India, after approval by the Institutional Animal Ethics Committee.

\section{Consent for publication}

All authors read and approved the final manuscript.

\section{Competing interests}

The authors declare that they have no competing interests.

\section{Publisher's Note}

Springer Nature remains neutral with regard to jurisdictional claims in published maps and institutional affiliations.

\section{Author details}

${ }^{1}$ Division of Cancer Stem Cells and Cardiovascular Regeneration, Manipal Institute of Regenerative Medicine, Manipal University, Bangalore 560 065, India. ${ }^{2}$ Stem Cell and Cancer Biology Laboratory, School of Biomedical Sciences, Curtin Health Innovation Research Institute, Curtin University, Perth, WA 6845, Australia. ${ }^{3}$ School of Anatomy, Physiology and Human Biology, Faculty of Science, The University of Western Australia, 35 Stirling Highway, Crawley, WA 6009, Australia. ${ }^{4}$ Cancer Science Institute of Singapore, National University of Singapore, Singapore 117599 , Singapore. ${ }^{5}$ Department of Pharmacology, Yong Loo Lin School of Medicine, National University of Singapore, Singapore 117597, Singapore. ${ }^{6}$ School of Biomedical Sciences, Curtin Health Innovation Research Institute, Curtin University, Perth, WA 6102, Australia. ${ }^{7}$ National University Cancer Institute, Singapore 119074, Singapore. ${ }^{8}$ Department of Biological Sciences, University of North Texas, Denton, TX 76203-5017, USA. ${ }^{9}$ Curtin Medical School, Faculty of Health Sciences, Curtin University, Perth, WA 6875, Australia.

Received: 24 May 2017 Revised: 14 July 2017 Accepted: 21 July 2017 Published online: 14 August 2017

\section{References}

1. Mozaffarian D, Benjamin EJ, Go AS, Arnett DK, Blaha MJ, Cushman M, et al.; American Heart Association Statistics Committee and Stroke Statistics Subcommittee. Heart disease and stroke statistics-2015 update: a report from the American Heart Association. Circulation. 2015; 131(4):e29-322.

2. Clifford DM, Fisher SA, Brunskill SJ, Doree C, Mathur A, Watt S, et al. Stem cell treatment for acute myocardial infarction. Cochrane Database Syst Rev. 2012;2:CD006536.

3. Ahuja P, Sdek P, MacLellan WR. Cardiac myocyte cell cycle control in development, disease, and regeneration. Physiol Rev. 2007;87(2):521-44.

4. Oh H, Bradfute SB, Gallardo TD, Nakamura T, Gaussin V, Mishina Y, et al. Cardiac progenitor cells from adult myocardium: homing, differentiation, and fusion after infarction. Proc Natl Acad Sci U S A. 2003;100(21):12313-8.

5. Senyo SE, Steinhauser ML, Pizzimenti CL, Yang VK, Cai L, Wang M, et al. Mammalian heart renewal by pre-existing cardiomyocytes. Nature. 2013;493(7432):433-6.

6. Dai W, Hale SL, Martin BJ, Kuang JQ, Dow JS, Wold LE, et al. Allogeneic mesenchymal stem cell transplantation in postinfarcted rat myo-cardium: short- and long-term effects. Circulation. 2005;112:214-23.

7. Cherry AB, Daley GQ. Reprogrammed cells for disease modeling and regenerative medicine. Annu Rev Med. 2013;64:277-90.

8. Hsieh JY, Fu YS, Chang SJ, Tsuang YH, Wang HW. Functional module analysis reveals differential osteogenic and stemness potentials in human mesenchymal stem cells from bone marrow and Wharton's jelly of umbilical cord. Stem Cells Dev. 2010;19(12):1895-910.

9. Castro-Manrreza ME, Mayani H, Monroy-García A, Flores-Figueroa E, ChávezRueda K, Legorreta-Haquet V, et al. Human mesenchymal stromal cells from adult and neonatal sources: a comparative in vitro analysis of their immunosuppressive properties against T cells. Stem Cells Dev. 2014;23(11):1217-32.

10. Willems E, Spiering S, Davidovics H, Lanier M, Xia Z, Dawson M, et al. Smallmolecule inhibitors of the Wnt pathway potently promote cardiomyocytes from human embryonic stem cell-derived mesoderm. Circ Res. 2011;109(4):360-4. 
11. Callis TE, Dongsun Cao D, Wang D. Bone morphogenetic protein signaling modulates myocardin transactivation of cardiac genes. Circ Res. 2005;97(10):992-1000.

12. Layman WS, Hurd EA, Martin DM. Chromodomain proteins in development: lessons from CHARGE Syndrome. Clin Genet. 2010;78(1):11-20.

13. Kitagawa $H$, Fujiki $R$, Yoshimura K. Williams syndrome is an epigenomeregulator disease. Endocr J. 2011;58(2):77-85.

14. Nimura K, Ura K, Shiratori H. A histone H3 lysine 36 trimethyltransferase links Nkx2-5 to Wolf-Hirschhorn syndrome. Nature. 2009;460:287-91.

15. Ordovás JM, Smith CE. Epigenetics and cardiovascular disease. Nat Rev Cardiol. 2010;7:510-9.

16. Wang HS, Hung SC, Peng ST, Huang CC, Wei HM, Guo YJ, et al. Mesenchymal stem cells in the Wharton's jelly of the human umbilical cord. Stem Cells. 2004;22(7):1330-7.

17. Warrier S, Haridas N, Bhonde R. Inherent propensity of amnion-derived mesenchymal stem cells towards endothelial lineage: vascularization from an avascular tissue. Placenta. 2012;33(10):850-8.

18. Bhuvanalakshmi G, Arfuso F, Dharmarajan A, Warrier S. Multifunctional properties of chicken embryonic prenatal mesenchymal stem cellspluripotency, plasticity, and tumor suppression. Stem Cell Rev. 2014;10(6):856-70.

19. Viola HM, Arthur PG, Hool LC. Transient exposure to hydrogen peroxide causes an increase in mitochondria-derived superoxide as a result of sustained alteration in L-type Ca2 channel function in the absence of apoptosis in ventricular myocytes. Circ Res. 2007;100(7):1036-44.

20. Horrillo A, Pezzolla D, Fraga MF, Aguilera Y, Salguero-Aranda C, Tejedo JR, et al. Zebularine regulates early stages of mESC differentiation: effect on cardiac commitment. Cell Death Dis. 2013;4:e570.

21. Desai VG, Herman EH, Moland CL, Branham WS, Lewis SM, Davis KJ, et al. Development of doxorubicin-induced chronic cardiotoxicity in the B6C3F1 mouse model. Toxicol Appl Pharmacol. 2013;266(1):109-21.

22. Bullock GR, Petrusz P. Techniques in Immunocytochemistry. London: Academic Press; 1982. p. v.

23. Daskalopoulos EP, Hermans KC, Janssen BJ, et al. Targeting the Wnt/frizzled signaling pathway after myocardial infarction:a new tool in the therapeutic toolbox? Trends Cardiovasc Med. 2013;23(4):121-7.

24. Laeremans $H$, Hackeng TM, van Zandvoort MA, Thijssen VL, Janssen BJ, Ottenheijm $\mathrm{HC}$, et al. Blocking of frizzled signaling with a homologous peptide fragment of wnt3a/wnt5a reduces infarct expansion and prevents the development of heart failure after myocardial infarction. Circulation. 2011;124(15):1626-35.

25. Kobayashi K, Luo M, Zhang Y, Wilkes DC, Ge G, Grieskamp T, et al. Secreted Frizzled-related protein 2 isa procollagen $C$ proteinase enhancer witha role in fibrosis associated withmyocardial infarction. Nat Cell Biol. 2009;11(1):46-55

26. He W, Zhang L, Ni A, Zhang Z, Mirotsou M, Mao L, et al. Exogenously administered secreted frizzled related protein 2 (Sfrp2) reduces fibrosis and improves cardiacfunction in a rat model of myocardial infarction. Proc Natl Acad Sci U S A. 2010:107(49):21110-5.

27. Matsushima K, Suyama T, Takenaka C, Nishishita N, Ikeda K, Ikada Y, et al. Secreted frizzled related protein 4 reduces fibrosis scar size and ameliorates cardiac function after ischemic injury. Tissue Eng Part A. 2010;16(11):3329-41.

28. Kaushik G, Spenlehauer A, Sessions AO, Trujillo AS, Fuhrmann A, Fu Z, et al Vinculin network-mediated cytoskeletal remodeling regulates contractile function in the aging heart. Sci Transl Med. 2015;7:292ra99.

29. Mouillet JF, Yan X, Ou Q, Jin L, Muglia L, Crawford PA, et al. DEAD-box protein103 (DP103, Ddx20)is essential for early embryonic development and modulates ovarianmorphology and function. Endocrinology. 2008;149(5):2168-75.

30. Fu JD, Yu HM, Wang R, Liang J, Yang HT. Developmental regulation of intracellular calcium transients during cardiomyocyte differentiation of mouse embryonic stem cells. Acta Pharmacol Sin. 2006:27(7):901-10.

31. Mujoo K, Sharin VG, Bryan NS, Krumenacker JS, Sloan C, Parveen S, et al. Role of nitric oxide signaling components in differentiation of embryonic stem cells into myocardial cells. Proc Natl Acad Sci U S A. 2008;105(48):18924-9.

32. Bloch W, Fleischmann BK, Lorke DE, Andressen C, Hops B, Hescheler J, et al. Nitric oxide synthase expression and role during cardiomyogenesis. Cardiovasc Res. 1999:43(3):675-84.

33. Kawamura T, Ono K, Morimoto T, Wada H, Hirai M, Hidaka K, et al. Acetylation of GATA4 is involved in the differentiation of embryonic stem cells into cardiac myocytes. J Biol Chem. 2005;280:19682-8.
34. Lints TJ, Parsons LM, Hartley L, Lyons I, Harvey RP. Nkx-2.5: a novel murine homeobox gene expressed in early heart progenitor cells and their myogenic descendants. Development. 1993;119(3):969.

35. Andrée B, Duprez D, Vorbusch B, Arnold HH, Brand T. BMP-2 induces ectopic expression of cardiac lineage markers and interferes with somite formation in chicken embryos. Mech Dev. 1998;70(1-2):119-31.

36. Karamboulas C, Swedani A, Ward C, Al-Madhoun AS, Wilton S, Boisvenue S, et al. HDAC activity regulates entry of mesoderm cells into the cardiac muscle lineage. J Cell Sci. 2006;119(Pt 20):4305-14.

37. Wamstad JA, Alexander JM, Truty RM, Shrikumar A, Li F, Eilertson KE, et al. Dynamic and coordinated epigenetic regulation of developmental transitions in the cardiac lineage. Cell. 2012;151(1):206-20.

38. Rice $\mathrm{KL}$, Hormaeche I, Licht JD. Epigenetic regulation of normal and malignant hematopoiesis. Oncogene. 2007;26(47):6697-714.

39. Liu Z, Li T, Liu Y, Jia Z, Li Y, Zhang C, et al. WNT signaling promotes Nkx2.5 expression and early cardiomyogenesis via downregulation of Hdac1. Biochim Biophys Acta. 2009:1793(2):300-11.

40. David R, Brenner C, Stieber J, Schwarz F, Brunner S, Vollmer M, et al. MesP1 drives vertebrate cardiovascular differentiation through Dkk-1-mediated blockade of Wnt-signalling. Nat Cell Biol. 2008;10(3):338-45.

41. Gibb N, Lavery DL, Hoppler S. sfrp1 promotes cardiomyocyte differentiation in Xenopus via negative-feedback regulation of Wnt signaling. Development. 2013;140(7):1537-49.

42. Brade T, Männer J, Kühl M. The role of Wnt signalling in cardiac development and tissue remodelling in the mature heart. Cardiovasc Res. 2006;72:198-209.

43. Naito AT, Shiojima I, Akazawa H, Hidaka K, Morisaki T, Kikuchi A, et al. Developmental stage-specific biphasic roles of Wnt/beta-catenin signaling in cardiomyogenesis and hematopoiesis. Proc Natl Acad Sci U S A. 2006:103:19812-7.

44. Bhuvanalakshmi G, Arfuso F, Millward M, Dharmarajan A, Warrier S. Secreted frizzled-related protein 4 inhibits glioma stem-like cells by reversing epithelial to mesenchymal transition, inducing apoptosis and decreasing cancer stem cell properties. PLoS One. 2015;10(6):e0127517.

45. Warrier S, Bhuvanalakshmi G, Arfuso F, Rajan G, Millward M, Dharmarajan A. Cancer stem-like cells from head and neck cancers are chemosensitized by the Wnt antagonist, sFRP4, by inducing apoptosis, decreasing stemness, drug resistance and epithelial to mesenchymal transition. Cancer Gene Ther. 2014;21(9):381-8.

46. Lian X, Hsiao C, Wilson G, Zhu K, Hazeltine LB, Azarin SM, et al. Robust cardiomyocyte differentiation from human pluripotent stem cells via temporal modulation of canonical Wnt signaling. Proc Natl Acad Sci U S A. 2012:109(27):E1848-57.

47. Klappacher GW, Lunyak W, Sykes DB, Saw ka-Verhelle D, Sage J, Brard G, et al. An induced Ets repressor complex regulates growth arrest during terminal macrophage differentiation. Cell. 2002;109(2):169-80.

48. Spallotta F, Rosati J, Straino S, Nanni S, Grasselli A, Ambrosino V, et al. Nitric oxide determines mesodermic differentiation of mouse embryonic stem cells by activating class Ila histonedeacetylases: potential therapeutic implications ina mouse model of hindlimb ischemia. Stem Cells. 2010;28(3):431-42

49. Mujoo K, Krumenacker JS, Wada Y, Murad F. Differential expression of nitric oxide signaling components in undifferentiated and differentiated human embryonic stem cells. Stem Cells Dev. 2006;15(6):779-87.

50. van Weerd JH, Koshiba-Takeuchi K, Kwon C, Takeuchi JK. Epigenetic factors and cardiac development. Cardiovasc Res. 2011;91:203-11.

51. Tzahor E. Wnt/beta-catenin signaling and cardiogenesis: timing does matter. Dev Cell. 2007;13:10-3

52. Jaspard B, Couffinhal T, Dufourcq P, et al. Expression pattern of mouse sFRP1 and mWnt-8 gene during heart morphogenesis. Mech Dev. 2000;90(2):263-7.

53. Schiefer L, Visweswaran M, Perumal V, Arfuso F, Groth D, Newsholme P, et al. Epigenetic regulation of the secreted frizzled-related protein family in human glioblastoma multiforme. Cancer Gene Ther. 2014;21(7):297-303.

54. Jost E, Schmid J, Wilop S, Schubert C, Suzuki H, Herman JG, et al. Epigenetic inactivation of secreted Frizzled-related proteins in acute myeloid leukaemia. Br J Haematol. 2008;142:745-53.

55. Vecellio M, Meraviglia V, Nanni S, Barbuti A, Scavone A, DiFrancesco D, et al, In vitro epigenetic reprogramming of human cardiac mesenchymal stromal cells into functionally competent cardiovascular precursors. PLoS One. 2012;7:e51694. 
56. Zhang S, Liu X, Bawa-Khalfe T, Lu LS, Lyu YL, Liu LF, et al. Identification of the molecular basis of doxorubicin-induced cardiotoxicity. Nat Med. 2012;18:1639-45

57. Mohammadi Gorji S, Karimpor Malekshah AA, Hashemi-Soteh MB, Rafiei A, Parivar K, Aghdami N. Effect of mesenchymal stem cells on Doxorubicininduced fibrosis. Cell J. 2012;14:142-51.

58. Kogata N, Arai Y, Pearson JT, Hashimoto K, Hidaka K, Koyama T, et al. Cardiac ischemia activates vascular endothelial cadherin promoter in both preexisting vascular cells and bone marrow cells involved in neovascularization. Circ Res. 2006;7:897-904.

59. Tomita S, Li RK, Weisel RD, Mickle DA, Kim EJ, Sakai T, et al. Autologous transplantation of bone marrow cells improves damaged heart function. Circulation. 1999; 100:1I-247-i-256.

60. Mias C, Lairez O, Trouche E, Roncalli J, Calise D, Seguelas MH, et al. Mesenchymal stem cells promote matrix metalloproteinase secretion by cardiac fibroblasts and reduce cardiac ventricular fibrosis after myocardial infarction. Stem Cells. 2009;27:2734-43.

61. Mangi AA, Noiseux N, Kong D, He H, Rezvani M, Ingwall JS, et al. Mesenchymal stem cells modified with Akt prevent remodeling and restore performance of infarcted hearts. Nat Med. 2003;9:1195-201.

Submit your next manuscript to BioMed Central and we will help you at every step:

- We accept pre-submission inquiries

- Our selector tool helps you to find the most relevant journal

- We provide round the clock customer support

- Convenient online submission

- Thorough peer review

- Inclusion in PubMed and all major indexing services

- Maximum visibility for your research

Submit your manuscript at www.biomedcentral.com/submit
Biomed Central 